\title{
Short term associations between outdoor air pollution and mortality in London 1992-4
}

\author{
S A Bremner, H R Anderson, R W Atkinson, A J McMichael, D P Strachan, J M Bland, \\ J S Bower
}

Department of Public Health Sciences, St George's Hospital Medical School, London, UK S A Bremner H R Anderson R W Atkinson D P Strachan

$\mathrm{J}$ M Bland

Epidemiology Unit, Department of Epidemiology and Population Health, London School of Hygiene and Tropical Medicine, London, UK A J McMichael

Air Quality Division, National

Environmental

Technology Centre, AEA Technology, Culham, Abingdon, Oxfordshire, UK J S Bower

Correspondence to: Mr SA Bremner,

Department of Public Health Sciences, St George's

Hospital Medical School,

Cranmer Terrace, London

SW17 ORE, UK. Telephone

0044181725 5424; fax

00441817253584

Accepted 12 November 1998

\begin{abstract}
Objectives-A previous study of the short term effects of air pollution in London from April 1987 to March 1992 found associations between all cause mortality and black smoke and ozone, but no clear evidence of specificity for cardiorespiratory deaths. London data from 1992 to 1994 were analysed to examine the consistency of results over time and to include particles with a mean aerodynamic diameter of $10 \mu \mathrm{m}\left(\mathbf{P M}_{10}\right)$ and carbon monoxide.
\end{abstract}

Methods-Poisson regression was used of daily mortality counts grouped by age and diagnosis, adjusting for trend, seasonality, calendar effects, deaths from influenza, meteorology, and serial correlation. The pollutants examined were particles $\left(\mathbf{P M}_{10}\right.$ and black smoke), nitrogen dioxide, ozone, sulphur dioxide, and carbon monoxide with single and cumulative lags up to 3 days.

Results-No significant associations were found between any pollutant and all cause mortality, but, with the exception of ozone, all estimates were positive. Each pollutant apart from ozone was significantly associated with respiratory mortality; $\mathbf{P M}_{10}$ showed the largest effect (4\% increase in deaths of all ages for a 10th-90th percentile increment). The pollutants significantly associated with cardiovascular deaths were nitrogen dioxide, ozone, and black smoke but there was no evidence of an association with $\mathbf{P M}_{10}$. In two pollutant models of respiratory deaths, the effect of black smoke, which in London indicates fine particles of diesel origin, was independent of that of $\mathbf{P M}_{10}$, but not vice versa.

Conclusion-These results from a new data set confirm a previous report that there are associations between various air pollutants and daily mortality in London. This new study found greater specificity for associations with respiratory and cardiovascular deaths, and this increases the plausibility of a causal explanation. However, the effects of ozone found in the earlier study were not replicated. The fraction of $\mathbf{P} \mathbf{M}_{10}$ which comprises black smoke accounted for much of the effect of $\mathbf{P M}_{10}$.

(Occup Environ Med 1999;56:237-244)

Keywords: mortality; air pollution; time series
In recent years, several studies from various countries have reported possible associations between ambient air pollutants and daily mortality. ${ }^{1-5}$ The fact and interpretation of these associations have both been questioned, ${ }^{67}$ but the prevailing view is that these associations cannot be explained entirely by statistical artefacts or confounding by other factors. A causal relation is supported by the consistency of effects across cities with different environments and coherence with studies of daily morbidity, together with some experimental evidence.

The increase in mortality which occurred in London during the smog episode of 1952 established beyond doubt that air pollution from the burning of coal could be harmful and this finding helped to implement abatement policies - such as the Clean Air Acts. ${ }^{8}$ By the 1990s traffic had become the main source of outdoor air pollution, and in a previous study for the period April 1987 to March 1992 we found that a measure of fine black particles (black smoke (BS)) and ozone were significantly and independently associated with daily mortality. ${ }^{9}$ There was little specificity for cardiorespiratory deaths.

London has advantages for the investigation of air pollution and daily mortality because it has a large population living within the topographical area of the Thames basin, and appropriate information on health and air pollution. In this paper we present a comprehensive analysis of daily mortality in London which includes, for the first time, data on particles with a mean aerodynamic diameter of 10 $\mu \mathrm{m}\left(\mathrm{PM}_{10}\right)$, and carbon monoxide. It forms part of a series investigating the coherence of the effects of air pollution on mortality, hospital admissions, accident and emergency presentations, and consultations with general practitioners.

\section{Methods}

Files of deaths in Greater London were obtained from the Office of National Statistics. Daily mortality counts between January 1992 and December 1994 were constructed for deaths from all causes other than accidents or violence (ninth revision of the international classification of diseases (ICD-9)<800), all respiratory diseases (ICD-9 460-519), chronic obstructive lung disease and asthma (ICD-9 490-496), lower respiratory infections (ICD-9 466, 480-86), all cardiovascular diseases (ICD-9 390-459), ischaemic heart disease (ICD-9 410-414), all cancers (ICD-9 140239), and all other causes (not already 

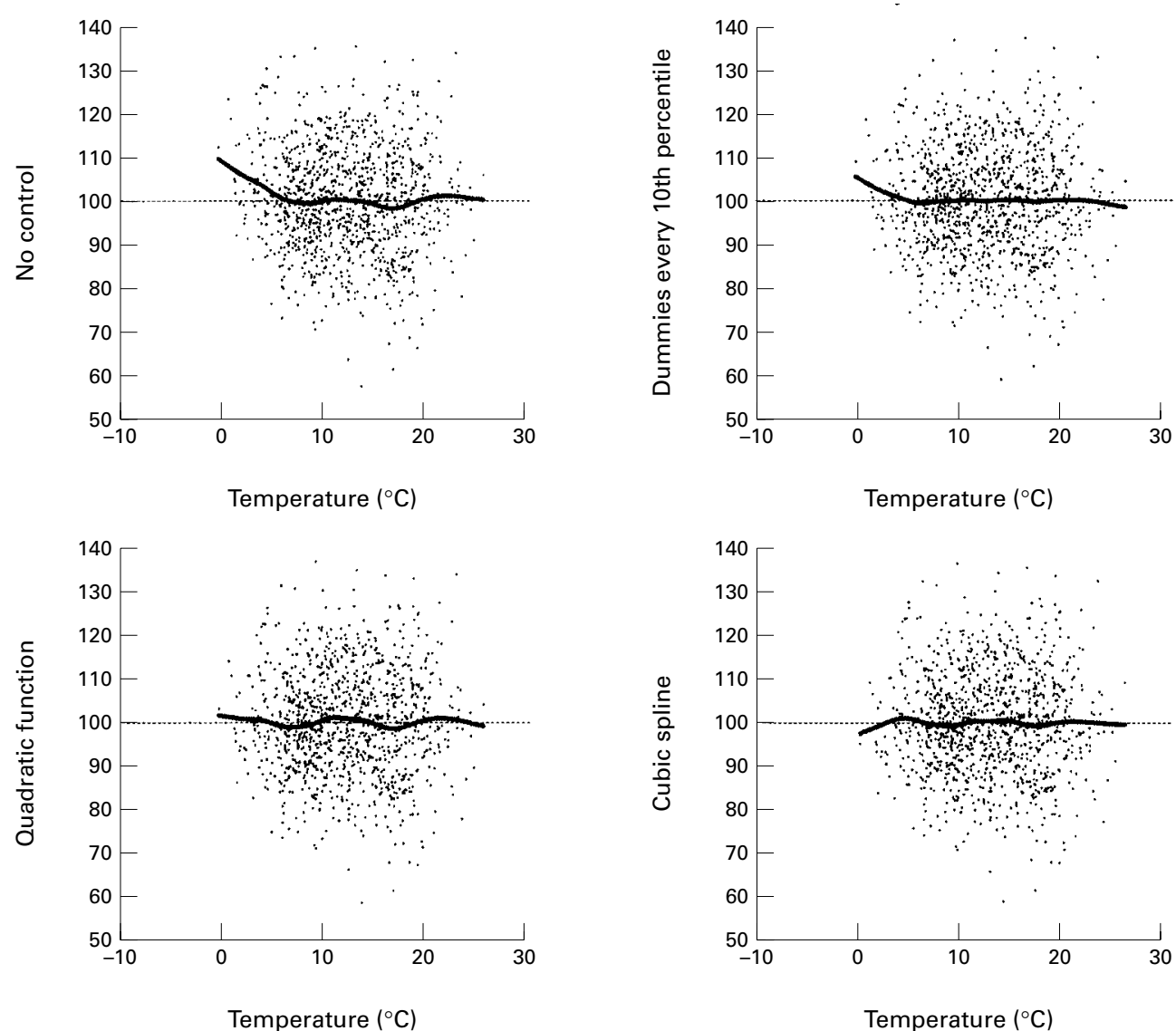

Figure 1 Relation between daily cardiovascular mortality and temperature at a lag of 2 days. Top left, no control for temperature. Top right, dummies every 10th percentile. Bottom left, quadratic function. Bottom right, cubic spline. The vertical axis on each panel is the observed mortality expressed as a percentage of that predicted by the model.

mentioned). The daily counts for each group were also subdivided by age; for the larger disease groups the age categories were: all-ages, $0-64, \geqslant 65,65-74$, and $\geqslant 75$. A total of 23 diagnostic age groups were analysed. Only the deaths of those resident and dying in Greater London (defined by Health Authority boundaries and covering a population of some 7 million people at the 1991 census) were included in the analysis.

Daily average values for temperature and humidity were calculated from daily maximum and minimum temperatures and 0600 and 1500 humidity measures from Holborn, Central London. Daily air pollution data were obtained from all London monitoring stations which measured background concentrations and had adequate $(>75 \%)$ days of data. Nitrogen dioxide $\left(\mathrm{NO}_{2}\right)$ and carbon monoxide (CO) were obtained from three sites and ozone $\left(\mathrm{O}_{3}\right)$ from two sites. Only one site (in Central London) provided data on $\mathrm{PM}_{10}$. Data on black smoke and $\mathrm{SO}_{2}$ were obtained from five sites. Missing values were estimated with a standard procedure ${ }^{10}$ and single daily average values of each pollutant were calculated. Further detailed information on sites and measurement methods are provided in a recent comprehensive review of United Kingdom air quality. ${ }^{11}$

The statistical approach followed that used by the APHEA project. ${ }^{12}$ The long term trend, seasonality, and day of week fluctuations of the mortality series were identified with several statistical tools. Spectral analysis was used to identify the seasonal patterns. Variables were constructed to account for these seasonal patterns and these were retained in a regression model only if significant. Counts of deaths due to influenza were included as a confounder. The fit of the model was assessed with the deviance, estimated dispersion parameter, and various plots of the residuals. The partial autocorrelation function was used to assess the presence of serial correlation.

In the next stage the relation with temperature was determined with spline smoothed plots of the observed mortality expressed as a percentage of that predicted by the model against single day and cumulative lag measures up to 2 days. Alternative ways of modelling temperature (dummy variables, linear, quadratic, piecewise, and cubic spline functions ${ }^{13}$ ) were investigated. Figure 1 presents four spline smoothed plots of temperature at lag 2 days obtained from the all cardiovascular all ages model building process. The top left panel shows the residuals from a model in which seasonal and calendar effects, but not temperature, have been controlled for. A shallow hockey stick shape relation was found. The top right panel indicates that this relation has not been adequately described by dummy variables. Use of a quadratic function is shown in the bottom left panel although a certain amount of systematic variation 
Table 1 Mean (SD) range and percentiles of deaths a day in London 1992-4 by diagnostic category and age group, pollution, and meteorological variables

\begin{tabular}{|c|c|c|c|c|c|c|c|}
\hline \multirow[b]{2}{*}{ Variables by ages } & \multicolumn{2}{|l|}{ Daily } & \multicolumn{5}{|c|}{ Percentile } \\
\hline & Mean & $(S D)$ & Min & 10th & Med & 90th & $\operatorname{Max}$ \\
\hline \multicolumn{8}{|c|}{ Main mortality series (ages): } \\
\hline \multicolumn{8}{|l|}{ All causes: } \\
\hline All & 169 & $(24)$ & 104 & 141 & 166 & 200 & 258 \\
\hline $0-64$ & 30 & (6) & 14 & 23 & 30 & 37 & 52 \\
\hline$\geqslant 65$ & 139 & (21) & 81 & 114 & 137 & 168 & 213 \\
\hline $65-74$ & 38 & (7) & 16 & 29 & 37 & 47 & 61 \\
\hline$\geqslant 75$ & 101 & (18) & 53 & 80 & 99 & 124 & 167 \\
\hline \multicolumn{8}{|l|}{ All respiratory: } \\
\hline All & 27 & (10) & 7 & 16 & 26 & 40 & 69 \\
\hline $0-64$ & 2.4 & (1.6) & 0 & 1 & 2 & 4 & 9 \\
\hline$\geqslant 65$ & 25 & (9) & 6 & 14 & 23 & 37 & 63 \\
\hline $65-74$ & 4.5 & $(2.5)$ & 0 & 2 & 4 & 8 & 15 \\
\hline$\geqslant 75$ & 20 & (8) & 4 & 11 & 19 & 31 & 56 \\
\hline \multicolumn{8}{|l|}{ All cardiovascular: } \\
\hline All & 73 & (13) & 35 & 57 & 73 & 89 & 112 \\
\hline $0-64$ & 10 & (3) & 2 & 6 & 10 & 14 & 22 \\
\hline$\geqslant 65$ & 63 & (11) & 32 & 49 & 63 & 78 & 100 \\
\hline $65-74$ & 16 & (4) & 4 & 11 & 16 & 22 & 32 \\
\hline$\geqslant 75$ & 47 & (9) & 21 & 35 & 46 & 59 & 78 \\
\hline \multicolumn{8}{|l|}{ All cancers } \\
\hline All & 44 & (7) & 23 & 35 & 44 & 53 & 71 \\
\hline \multicolumn{8}{|l|}{ All other causes: } \\
\hline All & 24 & (6) & 8 & 17 & 24 & 32 & 45 \\
\hline \multicolumn{8}{|c|}{ Pollution and meteorological variables: } \\
\hline $\mathrm{NO}_{2} 24 \mathrm{~h}(\mathrm{ppb})$ & 33.7 & (10.5) & 12.4 & 22.3 & 32.0 & 46.3 & 133.7 \\
\hline $\mathrm{NO}_{2} 1 \mathrm{~h}(\mathrm{ppb})^{\star}$ & 50.3 & $(17.0)$ & 22.0 & 34.3 & 47.0 & 70.3 & 224.3 \\
\hline $\mathrm{O}_{3} 8 \mathrm{~h}(\mathrm{ppb}) \dagger$ & 17.5 & $(11.5)$ & 1.9 & 4.4 & 16.0 & 30.1 & 79.9 \\
\hline $\mathrm{O}_{3} 1 \mathrm{~h}(\mathrm{ppb})^{\star}$ & 22.6 & $(13.4)$ & 2.5 & 6.0 & 21.5 & 36.5 & 98.5 \\
\hline $\mathrm{SO}_{2} 24 \mathrm{~h}\left(\mu \mathrm{g} / \mathrm{m}^{3}\right)$ & 21.2 & $(7.8)$ & 7.4 & 13.0 & 19.8 & 31.0 & 82.2 \\
\hline $\mathrm{CO} 24 \mathrm{~h}(\mathrm{ppm})$ & 0.8 & $(0.4)$ & 0.2 & 0.5 & 0.7 & 1.3 & 5.6 \\
\hline $\mathrm{PM}_{10} 24 \mathrm{~h}\left(\mu \mathrm{g} / \mathrm{m}^{3}\right)$ & 28.5 & $(13.7)$ & 6.8 & 15.8 & 24.8 & 46.5 & 99.8 \\
\hline BS $24 \mathrm{hr}\left(\mu \mathrm{g} / \mathrm{m}^{3}\right)$ & 12.7 & $(7.9)$ & 1.6 & 5.5 & 10.8 & 21.6 & 69.8 \\
\hline Temperature $\left({ }^{\circ} \mathrm{C}\right)$ & 11.9 & $(5.0)$ & -0.8 & 5.6 & 11.7 & 18.6 & 25.5 \\
\hline Humidity (\%) & 70.4 & $(11.0)$ & 33.0 & 56.0 & 70.0 & 85.0 & 97.0 \\
\hline
\end{tabular}

^Maximum 1 hour.

†Maximum 8 hour moving average.

remains. The chosen functional form for temperature is a cubic spline. The bottom right panel shows this to be adequate, except perhaps at the cold extreme. Also, it gave the lowest Aikakes' information criterion, a measure which considers the trade off between model fit and parsimony. Humidity was controlled for by a linear term at the same single or cumulative lag as temperature. More sophisticated control for humidity did not seem to be necessary, as judged from spline smoothed plots of model residuals against percentage humidity.

Once the core model comprising these variables had been completed, the air pollution variable was added and Poisson regression, allowing for overdispersion and auto-correlation, ${ }^{14}$ was used to estimate the relative risk associated with an increase in the pollution measure. This was expressed as a percentage change in the mean number of deaths for a 10th to 90 th percentile increase in the pollutant. The pollutant effect on the same day and 1,2, and 3 days before the day of the death (termed lag 0 to lag 3 ) as well as cumulative measures (defined as the mean of lags 0 and 1 , lags 0 to 2 , and lags 0 to 3 ) were all investigated.

This process of model building and pollutant testing was repeated for each outcome measure and age group combination. Possible modification of pollutant effect by season was investigated with a dummy variable to indicate the season (cool season defined as October to March and warm season as April to September). Where large and strongly significant associations were found, their robustness to the inclusion of other pollutants was tested by introducing the other pollutants in the model one at a time. All analyses were performed with SAS. ${ }^{15}$

Table 2 All year single pollutant, single lag results for all cause, all respiratory and all cardiovascular mortality (\% changes in relative risk estimates (death count) are for an increase in the pollutant from the 10th-90th percentile of its range)

\begin{tabular}{|c|c|c|c|c|c|c|c|c|c|c|c|c|c|}
\hline \multirow[b]{2}{*}{ Age group } & \multirow[b]{2}{*}{ Pollutant } & \multicolumn{4}{|c|}{ All causes } & \multicolumn{4}{|c|}{ All respiratory } & \multicolumn{4}{|c|}{ All cardiovascular } \\
\hline & & $\begin{array}{l}\text { Single } \\
\text { lagf }\end{array}$ & $\begin{array}{l}\text { \%Change in death } \\
\text { count }(95 \% \text { CI) }\end{array}$ & $p$ Value & $\begin{array}{l}\text { Season } \\
\text { effect }\end{array}$ & $\begin{array}{l}\text { Single } \\
\text { lagf }\end{array}$ & $\begin{array}{l}\% \text { Change in death } \\
\text { count }(95 \% \text { CI })\end{array}$ & $p$ Value & $\begin{array}{l}\text { Season } \\
\text { effect }\end{array}$ & $\begin{array}{l}\text { Single } \\
\text { lagf }\end{array}$ & $\begin{array}{l}\% \text { Change in death } \\
\text { count }(95 \% \text { CI) }\end{array}$ & $p$ Value & $\begin{array}{l}\text { Seasonal } \\
\text { Effect }\end{array}$ \\
\hline \multirow[t]{6}{*}{ All } & $\mathrm{NO}_{2}{ }^{\star}$ & 1 & $1.1(0.0$ to 2.3$)$ & 0.06 & & 3 & $2.3(-0.4$ to 5.0$)$ & 0.09 & & 1 & $2.3(0.7$ to 3.9$)$ & 0.006 & \\
\hline & $\mathrm{O}_{3} \dagger^{2}$ & 2 & $-0.7(-2.3$ to 0.9$)$ & 0.4 & & 2 & $-3.6(-7.7$ to 0.8$)$ & 0.1 & & 2 & $3.5(0.5$ to 6.7$)$ & 0.02 & $\mathrm{C}<\mathrm{W}$ \\
\hline & $\mathrm{SO}_{2}$ & 1 & $1.0(-0.3$ to 2.3$)$ & 0.1 & & 2 & $3.0(-0.1$ to 6.2$)$ & 0.06 & & 1 & $0.8(-1.0$ to 2.7$)$ & 0.4 & \\
\hline & $\mathrm{CO}^{2}$ & 1 & $0.9(-0.2$ to 2.0$)$ & 0.1 & & 3 & $2.0(-0.3$ to 4.5$)$ & 0.09 & & 1 & $1.4(-0.1$ to 3.0$)$ & 0.06 & \\
\hline & $\mathrm{PM}_{10}$ & 1 & $0.8(-0.6$ to 2.2$)$ & 0.3 & & 3 & $4.0(0.9$ to 7.3$)$ & 0.01 & $\mathrm{~W}<\mathrm{C}$ & 1 & $1.7(-0.2$ to 3.7$)$ & 0.09 & \\
\hline & BS & 1 & $1.2(0.0$ to 2.4$)$ & 0.06 & & 3 & $3.1(0.4$ to 6.0$)$ & 0.02 & & 1 & $1.9(0.2$ to 3.6$)$ & 0.03 & \\
\hline \multirow[t]{6}{*}{$0-64$} & $\mathrm{NO}_{2}^{\star}$ & 3 & $1.7(-0.7$ to 4.2$)$ & 0.2 & & 3 & $4.8(-3.5$ to 13.8$)$ & 0.3 & & 2 & $2.5(-1.7$ to 6.9$)$ & 0.2 & \\
\hline & $\mathrm{O}_{3} \mathrm{t}^{2}$ & 3 & $2.2(-1.3$ to 5.8$)$ & 0.2 & & 1 & $8.4(-6.4$ to 25.7$)$ & 0.3 & & 2 & $3.8(-2.7$ to 10.6$)$ & 0.3 & \\
\hline & $\mathrm{SO}_{2}$ & 2 & $-1.2(-3.9$ to 1.5$)$ & 0.4 & & 3 & $8.0(-1.5$ to 18.4$)$ & 0.1 & & 3 & $-2.2(-6.6$ to 2.3$)$ & 0.3 & \\
\hline & $\mathrm{CO}^{2}$ & 1 & $1.2(-1.0$ to 3.5$)$ & 0.3 & & 3 & $7.8(0.2$ to 15.9$)$ & 0.04 & & 2 & $2.1(-1.7$ to 6.0$)$ & 0.3 & \\
\hline & $\mathrm{PM}_{10}$ & 1 & $1.3(-1.7$ to 4.3$)$ & 0.4 & & 2 & $-7.2(-16.3$ to 2.9$)$ & 0.2 & & 2 & $2.7(-2.3$ to 8.0$)$ & 0.3 & \\
\hline & BS & 1 & $1.2(-1.4$ to 3.8$)$ & 0.4 & & 3 & $7.1(-1.6$ to 16.6$)$ & 0.1 & & 3 & $-3.4(-7.4$ to 0.9$)$ & 0.1 & \\
\hline \multirow[t]{6}{*}{$\geqslant 65$} & $\mathrm{NO}_{2}^{\star}$ & 1 & $1.0(-0.2$ to 2.3$)$ & 0.1 & & 3 & $1.4(-1.3$ to 4.2$)$ & 0.3 & & 0 & $2.4(0.7$ to 4.2$)$ & 0.006 & \\
\hline & $\mathrm{O}_{3} \dagger^{2}$ & 2 & $-1.3(-3.0$ to 0.5$)$ & 0.2 & $\mathrm{~W}<\mathrm{C}$ & 1 & $2.5(-2.3$ to 7.4$)$ & 0.3 & & 0 & $3.3(0.7$ to 6.0$)$ & 0.01 & \\
\hline & $\mathrm{SO}_{2}$ & 2 & $1.0(-0.3$ to 2.4$)$ & 0.1 & & 1 & $2.7(-0.6$ to 6.1$)$ & 0.1 & & 3 & $1.4(-0.5$ to 3.3$)$ & 0.2 & \\
\hline & $\mathrm{CO}^{2}$ & 2 & $0.8(-0.4$ to 1.9$)$ & 0.2 & $\mathrm{~W}<\mathrm{C}$ & 3 & $0.7(-1.7$ to 3.2$)$ & 0.6 & & 2 & $1.1(-0.4$ to 2.8$)$ & 0.2 & \\
\hline & $\mathrm{PM}_{10}$ & 0 & 0.7 ( -0.9 to 2.3$)$ & 0.4 & & 2 & $3.6(0.2$ to 7.2$)$ & 0.04 & & 0 & $1.2(-0.9$ to 3.3$)$ & 0.3 & \\
\hline & BS & 1 & $0.9(-0.4$ to 2.2$)$ & 0.2 & & 3 & $1.6(-1.2$ to 4.5$)$ & 0.3 & & 1 & $1.8(-0.1$ to 3.7$)$ & 0.06 & \\
\hline \multirow{6}{*}{$65-74$} & $\mathrm{NO}_{2}{ }^{\star}$ & 0 & $0.8(-1.5$ to 3.0$)$ & 0.5 & & 3 & $9.2(3.0$ to 15.8$)$ & 0.003 & & 1 & $3.3(0.0$ to 6.7$)$ & 0.05 & \\
\hline & $\mathrm{O}_{3} \dagger^{2}$ & 0 & $4.5(0.9$ to 8.3$)$ & 0.01 & & 2 & $9.9(-1.0$ to 21.9$)$ & 0.08 & & 1 & $5.5(0.6$ to 10.6$)$ & 0.03 & \\
\hline & $\mathrm{SO}_{2}$ & 1 & $1.3(-1.2$ to 4.0$)$ & 0.3 & & 1 & $7.3(-0.1$ to 15.2$)$ & 0.05 & & 1 & $1.7(-2.1$ to 5.6$)$ & 0.4 & \\
\hline & $\mathrm{CO}$ & 3 & $0.8(-1.2$ to 2.8$)$ & 0.5 & & 3 & $7.5(2.1$ to 13.2$)$ & 0.006 & & 2 & $2.4(-0.6$ to 5.5$)$ & 0.1 & \\
\hline & $\mathrm{PM}_{10}$ & 2 & $-1.3(-4.0$ to 1.4$)$ & 0.3 & & 3 & $11.4(3.6$ to 19.8$)$ & 0.004 & & 1 & $0.9(-3.0$ to 5.0$)$ & 0.6 & \\
\hline & BS & 3 & $1.4(-1.0$ to 3.7$)$ & 0.3 & & 3 & $11.7(5.3$ to 18.6$)$ & 0.0003 & & 2 & $3.2(-0.3$ to 6.8$)$ & 0.1 & \\
\hline \multirow[t]{6}{*}{$\geqslant 75$} & $\mathrm{NO}_{2}^{\star}$ & 1 & $0.8(-0.7$ to 2.3$)$ & 0.3 & & 1 & $1.7(-1.3$ to 4.8$)$ & 0.3 & & 0 & $2.4(0.3$ to 4.6$)$ & 0.02 & \\
\hline & $\mathrm{O}_{3} \dagger^{2}$ & 3 & $1.1(-1.0$ to 3.2$)$ & 0.3 & & 3 & $3.3(-0.9$ to 7.7$)$ & 0.1 & $\mathrm{C}<\mathrm{W}$ & 0 & $3.0(-0.4$ to 6.4$)$ & 0.08 & \\
\hline & $\mathrm{SO}_{2}$ & 2 & $1.3(-0.3$ to 2.9$)$ & 0.1 & & 0 & $5.3(1.7$ to 9.0$)$ & 0.004 & & 3 & $2.5(0.2$ to 4.8$)$ & 0.03 & \\
\hline & $\mathrm{CO}^{2}$ & 2 & $0.9(-0.4$ to 2.2$)$ & 0.2 & & 0 & $2.3(-0.5$ to 5.3$)$ & 0.1 & & 2 & $1.9(0.0$ to 3.9$)$ & 0.05 & \\
\hline & $\mathrm{PM}_{10}$ & 2 & $1.5(-0.2$ to 3.2$)$ & 0.08 & $\mathrm{~W}<\mathrm{C}$ & 2 & $4.3(0.7$ to 7.9$)$ & 0.02 & & 0 & $0.9(-1.5$ to 3.4$)$ & 0.5 & \\
\hline & BS & 0 & $1.0(-0.6$ to 2.5$)$ & 0.2 & & 3 & $0.7(-2.3$ to 3.7$)$ & 0.7 & & 1 & $2.1(-0.1$ to 4.3$)$ & 0.06 & \\
\hline
\end{tabular}

${ }^{\star}$ Maximum 1 hour; †maximum 8 hour moving average. $\ddagger$ Most significant lag, irrespective of direction of estimate.

Test for effect modification by season significant at the $5 \%$ level: $\mathrm{W}=$ warm season; $\mathrm{C}=$ cool season; $\mathrm{W}<\mathrm{C}=$ warm season effect is significantly less than cool season effect $(\mathrm{p}<0.05)$. 
Table 3 Results for two pollutant models for all respiratory and all cardiovascular mortality for all ages (percentage change in relative risk is for the row pollutant in the presence of the column pollutant; the \% change in risk is for a 10th-90th centile increase in the pollutant, 95\% CIs and $p$ values rounded to the first significant figure are also given.)

\begin{tabular}{|c|c|c|c|c|c|}
\hline Outcome & Pollutant and lag & Single pollutant results & $\mathrm{NO}_{2} 1$ hour & $\mathrm{O}_{3} 8$ hour & $\mathrm{SO}_{2} 24$ hour \\
\hline \multirow[t]{4}{*}{ All respiratory, all ages } & & & Lag 3 & Lag 2 & Lag 2 \\
\hline & $\mathrm{SO}_{2} 24$ hour lag 2 & $3.02(-0.09$ to 6.22$) 0.06$ & $1.80(0.09$ to 3.54$) 0.04$ & 2.14 (0.33 to 3.99$) 0.02$ & - \\
\hline & $\mathrm{PM}_{10} 24 \mathrm{~h}$ lag 3 & $4.01(0.85$ to 7.28$) 0.01$ & $1.22(-0.09$ to 2.55$) 0.07$ & $1.47(0.46$ to 2.50$) 0.004$ & $2.83(-0.25$ to 6.00$) 0.1$ \\
\hline & BS $24 \mathrm{~h}$ lag 3 & $3.14(0.41$ to 5.95$) 0.02$ & $1.26(-1.03$ to 3.60$) 0.3$ & $2.70(0.88$ to 4.54$) 0.003$ & $2.78(-0.10$ to 5.70$) 0.05$ \\
\hline \multirow{5}{*}{ All cardiovascular, all ages } & & & Lag 1 & Lag 2 & Lag 1 \\
\hline & $\mathrm{NO}_{2} 1 \mathrm{~h}$ lag 1 & 2.26 (0.65 to 3.91$) 0.006$ & - & 2.18 (0.75 to 3.64$) 0.01$ & 2.55 (0.40 to 4.75$) 0.01$ \\
\hline & $\mathrm{O}_{3} 8 \mathrm{~h}$ lag 2 & $3.52(0.48$ to 6.65$) 0.02$ & $3.71(0.58$ to 6.93$) 0.01$ & - & $4.00(0.85$ to 7.21$) 0.01$ \\
\hline & $\mathrm{PM}_{10} 24 \mathrm{~h}$ lag 1 & $1.70(-0.24$ to 3.67$) 0.09$ & $-0.31(-2.70$ to 2.14$) 0.8$ & $1.56(-0.27$ to 3.43$) 0.1$ & $0.93(-1.49$ to 3.42$) 0.4$ \\
\hline & BS $24 \mathrm{~h}$ lag 1 & $1.89(0.19$ to 3.62$) 0.03$ & $0.32(-1.86$ to 2.55$) 0.8$ & $1.56(0.04$ to 3.87$) 0.04$ & $1.78(-0.12$ to 3.71$) 0.07$ \\
\hline
\end{tabular}

\section{Results}

Table 1 summarises the distributions of the mortality series. Overall there were 184741 deaths for the calendar years 1992-4. Of these, $16 \%$ were attributed to respiratory and $43 \%$ to cardiovascular causes. Summary statistics for the air pollution and meteorological variables are also shown in table 1 . The Pearson correlation between monitoring sites was $0.83-0.87$ for $\mathrm{NO}_{2}$ (three sites), 0.96 for $\mathrm{O}_{3}$ (two sites), $0.7-0.89$ for $\mathrm{CO}$ (three sites), and $0.5-0.82$ for $\mathrm{BS}$ (five sites). For $\mathrm{SO}_{2}$ (five sites), one site did not correlate with any of the others but the correlation coefficients between the other four ranged from 0.22 to 0.51 . The various pollutants tended to be positively correlated except for $\mathrm{O}_{3}$ which was negatively associated with each of the other pollutants (all year correlation coefficient in the range -0.4 to 0 ) and especially during the cooler months (correlation coefficient between -0.55 and -0.47 ).

The associations between the various air pollutants and deaths from all causes and for respiratory and cardiovascular causes are shown in table 2 for the various age groups. For each pollutant modelled the lag with the most significant association, irrespective of direction of the estimate, is shown. Due to the
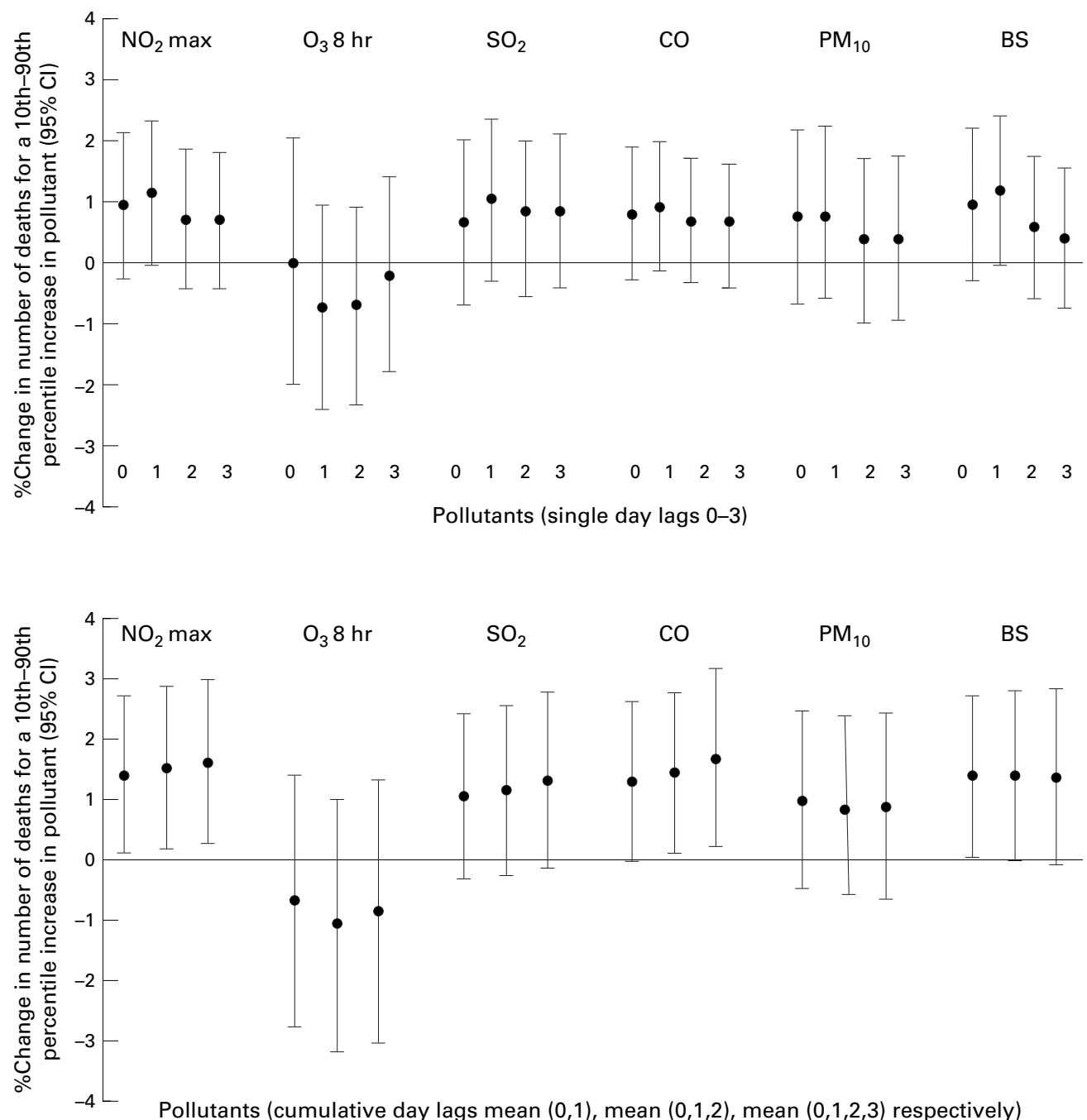

Figure 2 Percentage change in death count (95\% CI) of mortality from all causes and all ages for an increase from the 10 th to the 90th percentile across the range of each pollutant for all single lag (top panel) and cumulative lags (bottom panel) up to the third day. 
Table 3 continued

\begin{tabular}{lll}
\hline CO 24 hour & $P M_{10} 24$ hour & BS 24 hour \\
\hline Lag 3 & $\operatorname{Lag} 3$ & $\operatorname{Lag} 3$ \\
$1.90(0.18$ to 3.64$) 0.03$ & $2.55(-1.00$ to 6.23$) 0.2$ & $2.18(-1.01$ to 5.48$) 0.2$ \\
$1.25(0.04$ to 2.47$) 0.04$ & - & $1.25(-2.97$ to 5.65$) 0.5$ \\
$2.41(-0.65$ to 5.57$) 0.1$ & $3.25(-0.56$ to 7.21$) 0.1$ & - \\
Lag 1 & $\operatorname{Lag} 1$ & $\operatorname{Lag} 1$ \\
$2.55(0.40$ to 4.75$) 0.05$ & $2.18(0.04$ to 4.37$) 0.04$ & $1.82(-0.32$ to 4.00$) 0.08$ \\
$3.98(0.85$ to 7.21$) 0.01$ & $4.25(1.11$ to 7.48$) 0.009$ & $3.98(0.85$ to 7.21$) 0.009$ \\
$0.62(-0.59$ to 1.85$) 0.6$ & - & $0.62(-1.79$ to 3.10$) 0.7$ \\
$1.29(-1.53$ to 4.19$) 0.4$ & $1.29(-0.91$ to 3.54$) 0.3$ & - \\
\hline
\end{tabular}

multiplicity of pollutants and lags tested, the likelihood of finding significant results by chance is considerable. Therefore we place more emphasis on results significant at the $1 \%$ level and beyond and where there is some degree of consistency of effects across the range of lags. Note however that figures 2-4, which illustrate the lag structure of associations, show standard 95\% confidence intervals (95\% CIs) in accordance with those presented in tables 2 and 3. Results for the more specific diagnoses (chronic obstructive pulmonary disease (COPD) plus asthma, respiratory infection, ischaemic heart disease) are not shown but important associations will be referred to in the text. The full results for each diagnosis and all of the lags may be obtained from the authors.

In the all ages, all cause group all associations, except with $\mathrm{O}_{3}$, were positive, although small in magnitude (around 1\% increase for a 10th-90th percentile increment) and none were significant. As shown in figure 2 , all of the lags apart from those for $\mathrm{O}_{3}$ were consistent in that they all showed a similarly sized positive increase in mortality in association with an increase in pollution. Similarly for the 0-64 and $\geqslant 65$ age groups, the direction of the risk was, on the whole, positive but the magnitude small and none of the associations were significant.

All ages respiratory mortality was increased in association with all pollutants except $\mathrm{O}_{3}$. The significant finding was for $\mathrm{PM}_{10}$ with an estimate of $4.0 \%$ for a 10th-90th percentile increment of pollution. Figure 3 shows that the $\mathrm{PM}_{10}$ effects tended to increase steadily with increasing single day lags and cumulative lags. It also shows that the $\mathrm{SO}_{2}$ effect was consistently close to significance (at the $5 \%$ level). In the "younger" elderly (65-74) age group there
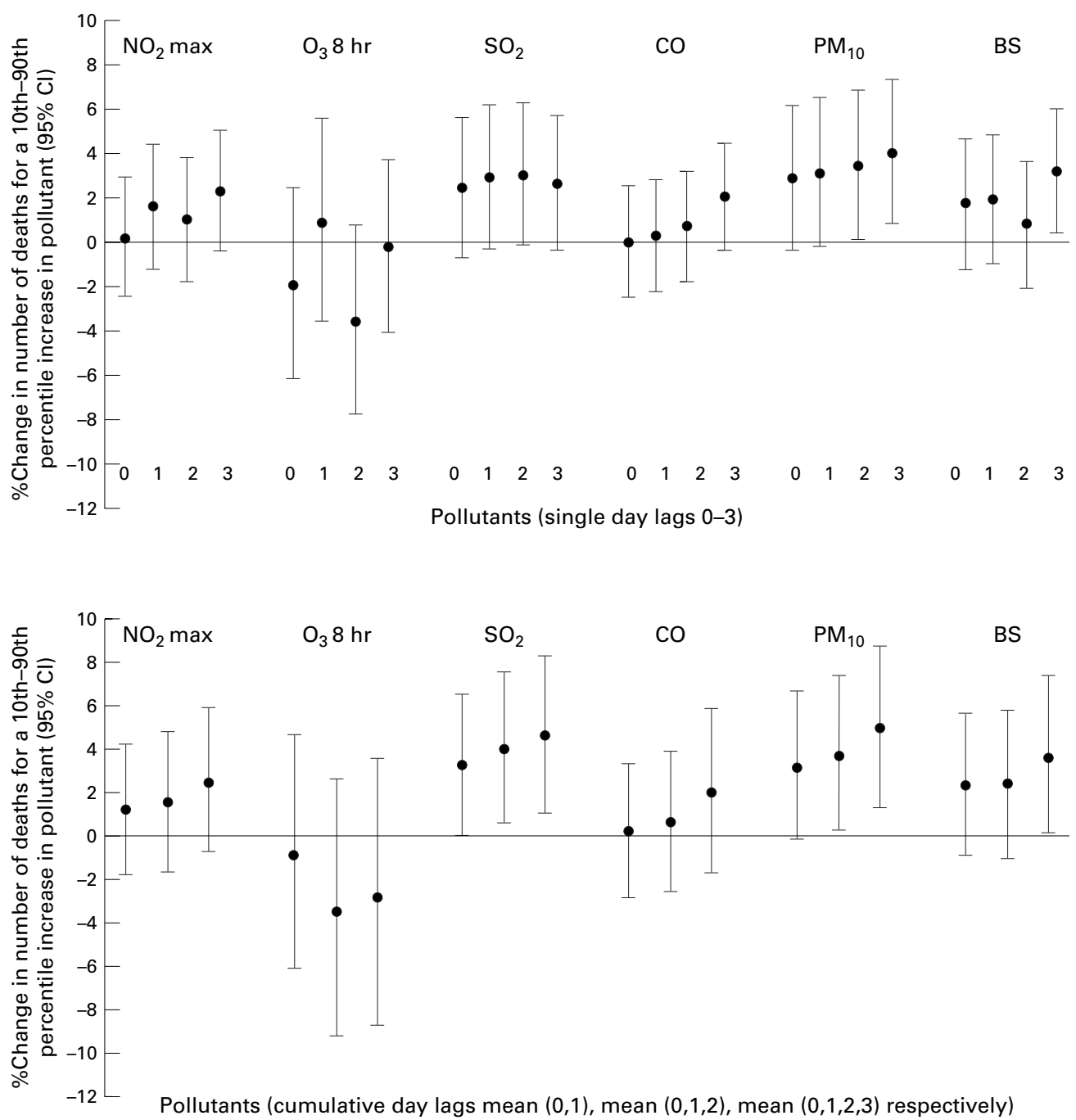

Figure 3 Percentage change in death count (95\% CI) of mortality from all respiratory all ages for an increase from the 10th to the 90th percentile across the range of each pollutant for all single lags (top panel) and cumulative lags (bottom panel) up to the third day. 

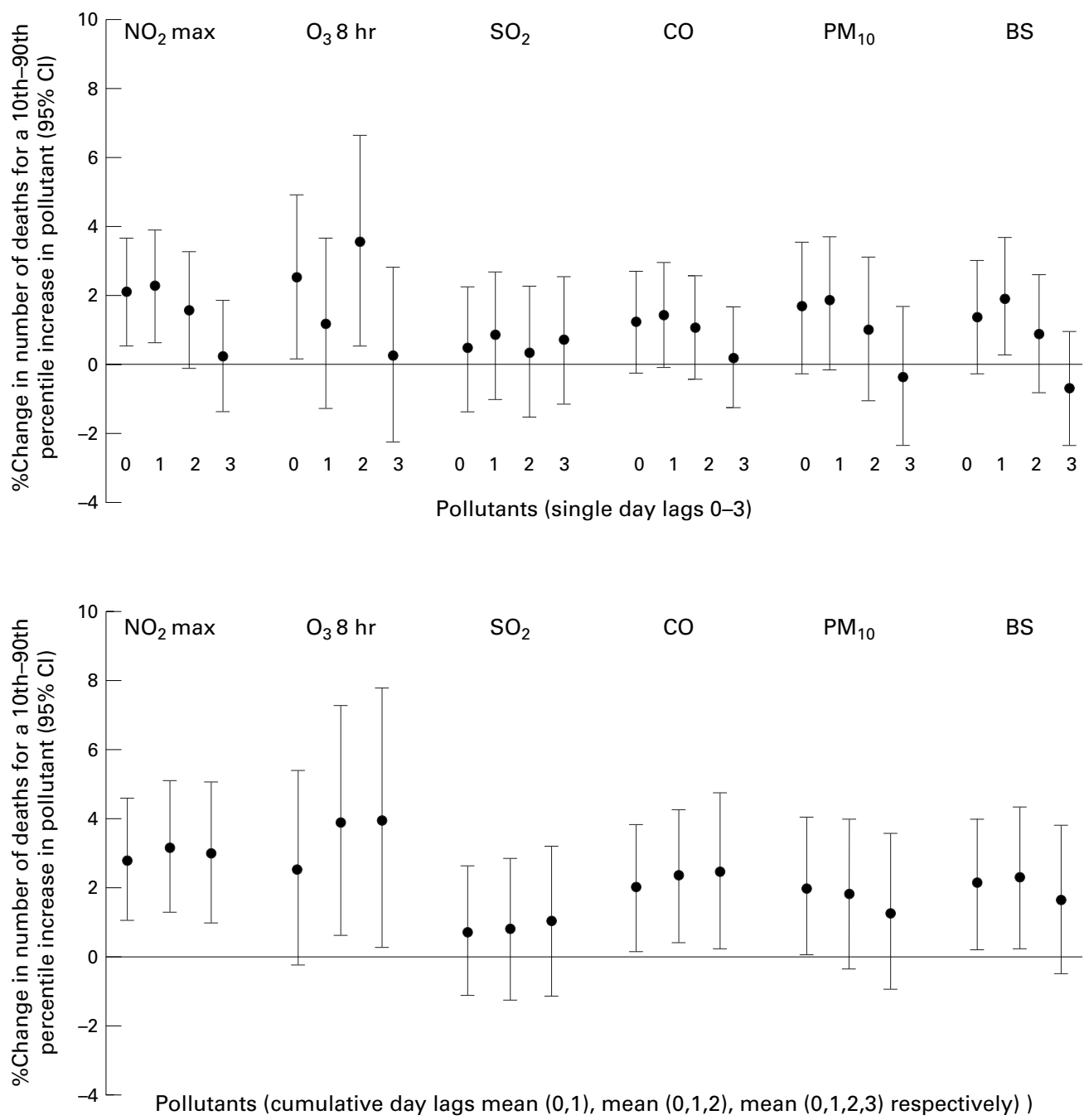

Figure 4 Percentage change in death count $(95 \%$ CI) of mortality from all cardiovascular all ages for an increase from the $10^{\text {th }}$ to the $90^{\text {th }}$ percentile across the range of each pollutant for all single lags (top panel) and cumulative lags (bottom panel) up to the third day.

were large and strongly significant associations with all the pollutants apart from $\mathrm{O}_{3}$ and $\mathrm{SO}_{2}$. By contrast, the "old" elderly group showed fewer and smaller associations, predominantly with $\mathrm{SO}_{2}$ and $\mathrm{PM}_{10}$. For mortality from COPD plus asthma in the $\geqslant 65$ age group, increases associated with $\mathrm{NO}_{2}, \mathrm{PM}_{10}$, and $\mathrm{BS}$ were $6.1 \%$ (95\% CI $1.3 \%$ to $11.1 \%) \mathrm{p}=0.01,7.8 \%(1.7 \%$ to $14.2 \%) \mathrm{p}=0.01$, and $6.2 \%(1.3 \%$ to $11.3 \%)$ $\mathrm{p}=0.01$, respectively. For deaths from lower respiratory infections, significant findings were found in the 0-64 age group where there were increases in daily mortality of $14.6 \%(3.1 \%$ to $27.3 \%) \quad p=0.01,18.3 \% \quad(4.4 \%$ to $34.1 \%)$ $\mathrm{p}=0.008,13.7 \%(3.6 \%$ to $24.8 \%) \mathrm{p}=0.007$, and $17.6 \%(5.1 \%$ to $31.6 \%) \mathrm{p}=0.005$ associated with $\mathrm{NO}_{2}, \mathrm{SO}_{2}, \mathrm{CO}$, and $\mathrm{BS}$, respectively, all at lag 3 days.

The effect estimates also tended to be positive for cardiovascular deaths, but the pattern of associated pollutants was different from that of respiratory deaths. For all ages, the most significant finding was for $\mathrm{NO}_{2}$, then $\mathrm{O}_{3}$ and BS. The cumulative lags were also associated with significant effects of $\mathrm{CO}$ and estimates for $\mathrm{PM}_{10}$ which were close to significance (fig 4). Associations between ischaemic heart disease and $\mathrm{NO}_{2}, \mathrm{O}_{3}, \mathrm{CO}$, and $\mathrm{BS}$ were positive and significant at the $5 \%$ level. Deaths from all cancers were not significantly associated with increases in air pollution. There were no significant associations with deaths from all other causes (not included in any of the other analyses), although risks tended to be increased at each lag for each pollutant.

Table 2 shows that the relative increase in daily all cause mortality was similar in the two elderly age groups. The main exceptions were for $\mathrm{O}_{3}$ for which the greater risk seemed to be in the younger elderly group and $\mathrm{PM}_{10}$ for which the estimate was greater among older elderly people. For respiratory mortality, the risks were consistently higher in young elderly than in old elderly people. For cardiovascular mortality there seems to be little difference between the two age groups.

The few estimates which differed significantly by season are indicated in table 2 . Some series, in particular those of respiratory causes may not have provided enough power to detect such differences due to small daily counts during the warm seasons. Full results are available on request. For deaths from all causes in the $\geqslant 65$ age group, the effect of $\mathrm{O}_{3}$ was 
significantly greater in the warm season (and in a positive direction) and that of $\mathrm{CO}$ was significantly less in the warm weather. In the all respiratory all ages category, the estimate for $\mathrm{PM}_{10}$ was $6.8 \%(95 \% \mathrm{CI} 2.7 \%$ to $11.0 \%)$ in the cool season, compared with $-0.2 \%(-5.0 \%$ to $4.8 \%$ ) in the warm season (difference $\mathrm{p}=0.04$ ). The effect of $\mathrm{O}_{3}$ on respiratory mortality in the $\geqslant 75$ age group was significantly higher in the warm season. For cardiovascular deaths, the effect of $\mathrm{O}_{3}$ was significantly greater in the warm season.

The correlation between the various pollutants makes it difficult to interpret their contribution to mortality with only single pollutant analyses. We therefore carried out selected analyses in which the effect of each pollutant that was significant on its own was examined when the other pollutants were included in the model. Table 3 shows the results of this analysis for the pollutants with the strongest effect on all age respiratory and cardiovascular mortality. Generally, there was a reduction in the magnitude and strength of association of the pollutant initially entered into the model. Overall no pollutant emerged as substantially more important than any other. However, the two indicators of particles tended to behave differently. The size of the BS effect was not affected by $\mathrm{PM}_{10}$ or the other pollutants, with the exception of $\mathrm{NO}_{2}$. On the other hand, the effect of $\mathrm{PM}_{10}$ was markedly reduced by including BS or other pollutants in the model. Thus, the effect of BS seemed to be more robust than that of $\mathrm{PM}_{10}$ in the two pollutant model.

In the cardiovascular deaths series, the effects of $\mathrm{NO}_{2}$ and BS were generally maintained in the presence of the other pollutants, except that BS was markedly affected by the inclusion of $\mathrm{NO}_{2}$ in the model. The effect of $\mathrm{O}_{3}$ was not affected and was even increased when other pollutants were included. $\mathrm{PM}_{10}$ was not significant in the single pollutant model and its effects were further reduced in size and significance in the two pollutant models.

\section{Discussion}

This comprehensive analysis of air pollution and daily mortality extends the results of earlier London studies and adds to the relatively few publications in which a wide range of pollutants have been examined in a large city in which the main primary pollutants are due to traffic. The statistical approach is now an accepted one ${ }^{16}$ but since our study began, other workers have increasingly used non-parametric approaches to control for seasonal and other confounders with generalised additive models. ${ }^{17}$ A study of daily mortality in Philadelphia which compared the two approaches, found that they gave similar results. ${ }^{18}$ Our own analyses which have applied the GAM method to selected series confirm that the results are not sensitive to the method used.

This study is unusual in finding no significant effect of any pollutant on all cause mortality. However, the estimate for BS $\left(+0.7 \%\right.$ for a $10 \mu \mathrm{g} / \mathrm{m}^{3}$ increment $)$ did not differ significantly from the earlier London study
$(+1.21 \%)^{9}$ or the APHEA meta-analysis of four European cities (London, Athens, Paris, and Barcelona) (+0.57\%). ${ }^{4}$ For $\mathrm{PM}_{10}$, the estimate was low $(+0.26 \%)$ compared with Birmingham, United Kingdom $(+1.1 \%)^{19}$ and a summary estimate of $+0.9 \%$ obtained from 17 (mainly) United States cities, ${ }^{20}$ but was closer to that of $+0.4 \%$ obtained from a metaanalysis of five western European cities (Barcelona, Cologne, Lyon, Milan, and Paris). ${ }^{4}$ Although not significant, the estimates for $\mathrm{NO}_{2}$ and $\mathrm{SO}_{2}$ were close to the APHEA estimates for seven and six European cities, respectively.

The lack of an association between $\mathrm{O}_{3}$ and all cause mortality in the present analysis contrasts with the significant effects found in other European cities-such as Athens and Barcelona. ${ }^{5}$ On the other hand, this result for ozone was consistent with the results of a meta-analysis of five United States cities which concluded that the effect of $\mathrm{O}_{3}$ on mortality was negligible. ${ }^{20}$ Although the earlier London study reported significant associations between mortality and $\mathrm{O}_{3},{ }^{9} t$ tests to compare the regression coefficients with those from the present study showed that our results do not contradict those of the earlier study. For all cause mortality there was weak evidence of a difference in effect $(p=0.04)$ but not for all respiratory and all cardiovascular mortality $(p=0.08$ and $p=0.29$, respectively). The earlier London study reported the most significant positive lag, which was the criteria on which we based the $t$ tests. However, the present study reports the most significant lag, irrespective of direction. Further, the distribution of $\mathrm{O}_{3}$ did not differ markedly between the two periods.

The largest and most significant relative risks were found among respiratory deaths and in this group the most important pollutants seemed to be particles and $\mathrm{SO}_{2}$. Cardiovascular deaths were affected to a lesser extent and $\mathrm{NO}_{2}$ and $\mathrm{O}_{3}$ seemed to be the most important pollutants. No associations were found with cancer deaths or all other causes of death, which tend to confirm the specificity for respiratory and cardiovascular deaths reported in many other studies and summarised by Dockery and Pope. ${ }^{21}$ Very large effects were found in some of the diagnostic subcategories of respiratory deaths.

Seasonal interactions between daily mortality and air pollutants have often been reported and various explanations postulated. These include differences in statistical power, the existence of threshold effects, confounding by other pollutants or weather factors, or complex interactions between pollutants. In the case of particles, the mixture is likely to vary in distribution of size and number and chemical composition..$^{22}$ In this study, we found few significant seasonal differences, the most prominent being stronger effects of $\mathrm{O}_{3}$ on cardiovascular deaths in the summer and of $\mathrm{PM}_{10}$ on respiratory deaths in the winter.

The pollutants examined in this study tended to be correlated. For respiratory mortality, we compared single pollutant with two pollutant models and found that inclusion of one pollutant in the model tended to make 
the effect of the other pollutant smaller and non-significant. Thus, we were unable to separate the effects of particles from those of $\mathrm{SO}_{2}$. This resembles the results of the analysis of Philadelphia data in which it proved difficult to disentangle the effects of particles, measured as total suspended particulates, from those of $\mathrm{SO}_{2} \cdot{ }^{17}$

There is increasing evidence that the health effects of $\mathrm{PM}_{10}$ may be due to components of the fine $\left(\mathrm{PM}_{2.5}\right)$ fraction. ${ }^{23}$ In London the fine fraction would come from primary emissions from mobile sources or secondary sources including long range transport of sulphates. ${ }^{22}$ The BS technique measures fine particles $(<4.5 \mu \mathrm{m}$ in diameter) which are black, and in London these are largely from traffic and more specifically diesel engines. ${ }^{24}$ Non-black particles such as sulphates are not measured by the BS method. The daily correlation between BS and $\mathrm{PM}_{10}$ was 0.61 . In the two pollutant models we found evidence that the effects of BS were robust to inclusion of $\mathrm{PM}_{10}$ in the model, but not vice versa. This is consistent with the idea that BS is more specific for fine particles whereas $\mathrm{PM}_{10}$, including the particles measured by the BS method, also includes a considerable component of non-relevant particles in the coarse fraction. Unfortunately, daily sulphate concentrations for London were incomplete and could not be included in this analysis. Current modelling work with sulphate data from rural monitors in the south east of England will eventually provide data to complement existing measures of particles. Future time series analyses will be able to use data on $\mathrm{PM}_{2.5}$ and particle counts from newly established measurement systems.

Elderly people are generally considered to be a sensitive subgroup because they have a higher prevalence of cardiorespiratory conditions, which together with age related declines in physiological reserves, places them at risk of dying when subject to additional factors - such as air pollution. When these groups were compared (table 2), it was found that the relative risks were if anything higher in the younger elderly than in the older elderly groups. However, the number of deaths was three to four times greater in the older elderly group (table 1); this means that the attributable deaths were considerably greater in the older group. Similarly, the numbers of cardiovascular deaths were two to three times higher than those of respiratory deaths; thus, although the relative risk estimates are greater for respiratory deaths, the attributable deaths are greater among the cardiovascular deaths. Younger elderly people, however, seem to be more susceptible to the effects of air pollution as judged by the relative risks than their older counterparts who could perhaps be seen as healthy survivors.

It is concluded that there are detectable associations between various air pollutants and daily mortality in London in the 1990s. The relative risks are highest in respiratory causes then cardiovascular causes, with little evidence of effects on other causes. The greatest absolute impact is on cardiovascular deaths because these have the highest baseline rate. All pollutants examined were found to have significant effects, but the most convincing results were the associations between particles and respiratory deaths, and between $\mathrm{NO}_{2}$ and $\mathrm{O}_{3}$ and cardiovascular deaths. Future studies should attempt to identify which component of the particle mixture is important.

This study was funded by the Department of Health (JR 121/6267). The collaboration comprised HR Anderson (principal investigator), AJ McMichael, DP Strachan, JM Bland, A Haines, J Emberlin, and J Bower. We thank Liz Limb for assisting us with preparing the mortality data, and Roger Newson, Jan Poloniecki, and Antonio Ponce de Leon for statistical advice.

1 American Thoracic Society. Health effects of outdoor air pollution. Am r Crit Care Med 1996;153:3-50.

pollution. Am r Crit Care Med 1996;153:3-50.
2 Pope CA3, Bates DV, Raizenne ME. Health effects of particulate air pollution: time for reassessment? Environ particulate air pollution: time for

3 Brunekreef B, Dockery DW, Krzyzanowski M. Epidemiologic studies on short-term effects of low levels of major ambient air pollution components. Environ Health Perspect 1995;103(suppl 2):3-13.

4 Katsouyanni K, Touloumi G, Spix C, et al. Short-term effects of ambient sulphur dioxide and particulate matter on mortality in 12 European cities: results from time series data from the APHEA project. Air pollution and health: a European approach. BMF 1997;314:1658-63.

5 Touloumi G, Katsouyanni K, Zmirou D, et al. Short-term effects of ambient oxidant exposure on mortality: a combined analysis within the APHEA project. Air pollution and health: a European approach. Am f Epidemiol

6 Moolgavkar SH, Luebeck EG, Hall TA, et al. Air pollution and daily mortality in Philadelphia. Epidemiology 1995;6: $476-84$

7 Gamble JF, Lewis RJ. Health and respirable particulate $\left(\mathrm{PM}_{10}\right)$ air pollution: a causal or statistical association? Environ Health Perspect 1996;104:838-50.

8 Ministry of Health. Mortality and morbidity during the London fog of December 1952. London: HMSO, 1954. (Reports on Public Health and Medical Subjects No 95.)

9 Anderson HR, Ponce de Leon A, Bland JM, et al. Air pollution and daily mortality in London: 1987-92. BMF 1996;312:665-9.

10 Buck SF. A method of estimation of missing values in multivariate data suitable for use with an electronic computer. Fournal of the Royal Statistical Society (B) 1960;22:302-6.

11 National Centre for Environmental Technology. Air pollution in the UK, 1996. AEA Technology, 1998. (AEAT 2238; ISBN 07058 1756 3.)

12 Katsouyanni K, Schwartz J, Spix C, et al. Short term effects of air pollution on health: a European approach using epiof air pollution on health: a European approach using epimiol Community Health 1996;50 (suppl 1):S12-8.

13 Diol Community Health 1996;50(suppl 1):S12-8. Durrleman S, Simon R. Flexible regre
cubic splines. Stat Med 1989;8:551-61.

14 Zeger SL. A regression model for time series of counts. Biometrika 1988;75:621-9.

15 SAS Institute. SAS/STAT user's guide, version 6 volume 2. Cary, NC: SAS Institute, 1989:846.

16 Schwartz J, Spix C, Touloumi G, et al. Methodological issues in studies of air pollution and daily counts of deaths or hospital admissions. F Epidemiol Community Health 1996;50 (suppl 1):S3-11.

17 Kelsall JE, Samet JM, Zeger SL, et al. Air pollution and mortality in Philadelphia, 1974-88. Am 7 Epidemiol 1997;146:750-62.

18 Health Effects Institute. Particulate air pollution and daily mortality: analysis of the effects of weather and multiple air pollutants. Boston, MA: Health Effects Institute, 1997.

19 Wordley J, Walters S, Ayres JG. Short term variations in hospital admissions and mortality and particulate air polluhospital admissions and mortality and particu

20 Schwartz J. Health effects of air pollution from traffic: ozone and particulate matter. In: Fletcher AC, McMichael AJ, eds. Health at the crossroads: transport policy and urban health. Chichester: Wiley, 1997:61-85.

21 Dockery D, Pope CA. Epidemiology of acute health effects: summary of time-series studies. In: Wilson R, Spengler J, eds. Particles in our air. Boston: Harvard University Press, 1996;123-47.

22 Quality of Urban Air Review Group. Urban air quality in the United Kingdom. Bradford: Department of the Environment, 1993.

23 Schwartz J, Dockery DW, Neas LM. Is daily mortality associated specifically with fine particles? I Air Waste Manag Assoc 1996;46:927-39.

24 Quality of Urban Air Review Group. Diesel vehicle emissions and urban air quality. Birmingham: Institute of Public and Environmental Health, University of Birmingham, 1993. 